\title{
What is the probability that two elements of a finite ring have product zero?
}

\author{
Sanhan Muhammad Salih Khasraw* \\ Department of Mathematics, College of Education, Salahaddin University-Erbil, Erbil, Kurdistan Region Iraq \\ *Corresponding author: sanhan.khasraw@su.edu.krd
}

\section{Article history}

Received 23 March 2020

Revised 21 April 2020

Accepted 14 May 2020

Published Online 27 August 2020

\begin{abstract}
In this paper, the probability that two elements of a finite ring have product zero is considered. The bounds of this probability are found for an arbitrary finite commutative ring with identity 1 . An explicit formula for this probability in the case of $Z_{n}$, the ring of integers modulo $n$, is obtained.
\end{abstract}

Keywords: Zero-divisor, zero-divisor graph, probability.

(c) 2020 Penerbit UTM Press. All rights reserved

\section{INTRODUCTION}

In a previous research, the problem of finding the probability that two elements of a finite group $G$ commute, $P(G)$ was considered by Gustafson [1], where he showed that $\mathrm{P}(\mathrm{G}) \leq 5 / 8$. For more studies about probability and group theory, see [2, 3]. Beck in [4] introduced the notion of zero-divisor graphs of a commutative ring. The zero-divisor graph is a graph with non-zero zero-divisors vertices, in which two vertices are adjacent if their product is zero. Zero-divisor graph of a commutative ring has been studied by many authors, see [6, $5,7]$. The idea of the study of zero-divisor graph of rings helps to study the probability that two elements of a finite ring $R$ have product zero in which for both cases depend on the products of elements of a ring which results in zero.

In this paper, the probability that two elements chosen at random (with replacement) from a ring $\mathrm{R}$ have product zero which is $P(R)=\frac{|A n n|}{|R \times R|}$, where Ann $=\{(x, y) \in R \times R \mid x y=0\}$ is considered. This idea has been considered in [8] where the authors found the structures of rings $R$ having maximum or minimum value of $\mathrm{P}(\mathrm{R})$ among all rings with identity of the same size. Also, they found $P(R)$ for the case of $R$ is a PIR local ring.

For each $\mathrm{X} \in \mathrm{R}$, the number of elements of Ann of the form $(\mathrm{x}, \mathrm{y})$ is $|\operatorname{Ann}(\mathrm{x})|$, where $\operatorname{Ann}(\mathrm{x})$ is the annihilator of $\mathrm{X}$ in $\mathrm{R}$. Hence $\mid$ Ann $\left|=\sum_{\mathrm{x} \in \mathrm{R}}\right| \operatorname{Ann}(\mathrm{x}) \mid$, where the sum is taken over all $x \in R$. Note that if $x y=0$, then both $(x, y)$ and $(\mathrm{y}, \mathrm{x})$ are elements of Ann .

Throughout this paper, all rings are assumed to be finite and commutative with identity 1 to establish lower and upper bounds of
$\mathrm{P}(\mathrm{R})$. Furthermore, the identity element 1 is assumed different from 0 , as the zero ring is a finite commutative ring with identity (namely 0 since $0 \cdot 0=0$ ) and the corresponding probability that two elements multiply to 0 is 1 . Also in the case where a ring $R$ does not have an identity element, the probability that two elements multiply to 0 can be 1 , for instance, if $R$ is a ring such that $a b=0$ for all $a, b \in R$, then $P(R)=1$. These two cases are exempted throughout this paper in order to investigate the minimum and maximum values of $\mathrm{P}(\mathrm{R})$.

\section{Bounds for $P(R)$}

In this section, the general lower and upper bounds for $\mathrm{P}(\mathrm{R})$ will be determined.

Theorem 2.1 Suppose $|\mathrm{R}|=\mathrm{n}$. Then

$P(R) \geq \frac{2 n+|Z(R)|-1}{n^{2}}$, where $Z(R)$ is the set of non-zero zero-divisors of $\mathrm{R}$.

Proof. It is clear that $|A n n(0)|=n$. Suppose $Z(R)$ be the set of non-zero zero-divisors of $R$. For every $x \in Z(R)$ we have that $|\operatorname{Ann}(\mathrm{x})| \geq 2$, and $|\operatorname{Ann}(\mathrm{x})|=1$ for each $0 \neq \mathrm{x} \notin \mathrm{Z}(\mathrm{R})$. Thus,

$|\operatorname{Ann}|=|\operatorname{Ann}(0)|+\sum_{x \in Z(R)}|\operatorname{Ann}(x)|+\sum_{0 \neq x \notin Z(R)}|\operatorname{Ann}(x)|$ 
$\geq \mathrm{n}+2 \cdot|\mathrm{Z}(\mathrm{R})|+(\mathrm{n}-1-|\mathrm{Z}(\mathrm{R})|) \cdot 1=2 \mathrm{n}+|\mathrm{Z}(\mathrm{R})|-1$.

Therefore, $\mathrm{P}(\mathrm{R})=\frac{|\mathrm{Ann}|}{\mathrm{n}^{2}} \geq \frac{2 \mathrm{n}+|\mathrm{Z}(\mathrm{R})|-1}{\mathrm{n}^{2}}$.

Theorem 2.2 Suppose $|\mathrm{R}|=\mathrm{n}$. Then

$P(R) \leq \frac{2 n+(m-1)|Z(R)|-1}{n^{2}}$, where $Z(R)$ is the set of

non-zero zero-divisors of $\mathrm{R}$, and

$\mathrm{m}=\max \{|\operatorname{Ann}(\mathrm{x})|: \mathrm{x} \in \mathrm{Z}(\mathrm{R})\}$.

Proof. Suppose $|\mathrm{R}|=\mathrm{n}$. Again, $|\operatorname{Ann}(0)|=\mathrm{n}$, and let the number of non-zero zero-divisors of $\mathrm{R}$ be $\mathrm{k}$, that is, $\mathrm{k}:=|\mathrm{Z}(\mathrm{R})|$. Suppose that $\mathrm{m}:=\max \{|\operatorname{Ann}(\mathrm{x})|: \mathrm{x} \in \mathrm{Z}(\mathrm{R})\}$. Note that $\mathrm{k}$ and $\mathrm{m}$ vary as $\mathrm{n}$ varies. Thus,

$|\operatorname{Ann}|=|\operatorname{Ann}(0)|+\sum_{x \in Z(R)}|\operatorname{Ann}(x)|+\sum_{0 \neq x \notin Z(R)}|\operatorname{Ann}(x)|$ $\leq \mathrm{n}+\mathrm{m} \cdot \mathrm{k}+(\mathrm{n}-1-\mathrm{k}) \cdot 1=2 \mathrm{n}+(\mathrm{m}-1) \mathrm{k}-1$. So, $P(R) \leq \frac{2 n+(m-1) k-1}{n^{2}}$.

Corollary 2.3 If $R$ is a finite ring with $|R|=n$, then $\mathrm{P}(\mathrm{R}) \leq \frac{3}{4}$

Proof. Since $\operatorname{Ann}(x)$ is an ideal of $R$ for any $x \in R$, it must be the case that $m=\max \{|\operatorname{Ann}(\mathrm{x})|: \mathrm{x} \in \mathrm{Z}(\mathrm{R})\} \leq \frac{1}{2} \mathrm{n}$ and, in general, $\mathrm{k}=|\mathrm{Z}(\mathrm{R})| \leq \mathrm{n}-2$, for then, by Theorem 2.2, $P(R) \leq \frac{2 n+\left(\frac{1}{2} n-1\right)(n-2)-1}{n^{2}}=\frac{1}{2}+\frac{1}{n^{2}} \quad$ which $\quad$ is decreasing as $n$ increases. If $n=2$, then $P(R) \leq \frac{3}{4}$.

From Theorem 2.1 and Theorem 2.2, the following corollaries can be deduced.

Corollary 2.4 If $R$ is an integral domain and $|R|=n$, then

$\mathrm{P}(\mathrm{R})=\frac{2 \mathrm{n}-1}{\mathrm{n}^{2}}$.

Proof. Since $R$ is an integral domain, then $|Z(R)|=0$. Thus, $\frac{2 \mathrm{n}-1}{\mathrm{n}^{2}} \leq \mathrm{P}(\mathrm{R}) \leq \frac{2 \mathrm{n}-1}{\mathrm{n}^{2}}$. The result follows.
For the non-integral domain case, if all annihilators have size $\mathrm{m}$, then the inequalities of Theorem 2.1 and Theorem 2.2 lead to the following.

Corollary 2.5 If $\mathrm{R}$ is a non-integral domain, $|\mathrm{R}|=\mathrm{n}$ and $|\operatorname{Ann}(\mathrm{x})|=\mathrm{m} \quad$ for $\quad$ all $\quad \mathrm{x} \in \mathrm{Z}(\mathrm{R})$, then $P(R)=\frac{2 n+(m-1) k-1}{n^{2}}$.

Next, the following theorem of computing the probability of direct product of rings is needed for the following section.

Theorem 2.6 Let $\mathrm{R}=\mathrm{R}_{1} \times \mathrm{R}_{2}$, where $\mathrm{R}_{1}$ and $\mathrm{R}_{2}$ are rings. Then $\mathrm{P}(\mathrm{R})=\mathrm{P}\left(\mathrm{R}_{1}\right) \mathrm{P}\left(\mathrm{R}_{2}\right)$.

Proof. Recall that $P(R)=\frac{\mid \text { Ann } \mid}{|R \times R|}$, where Ann $=\left\{\left(\left(\mathrm{r}_{1}, \mathrm{~s}_{1}\right),\left(\mathrm{r}_{2}, \mathrm{~s}_{2}\right)\right) \in \mathrm{R} \times \mathrm{R} \mid\left(\mathrm{r}_{1} \mathrm{r}_{2}, \mathrm{~s}_{1} \mathrm{~s}_{2}\right)=(0,0)\right\}$. Rewrite Ann in terms of $\operatorname{Ann}\left(\mathrm{R}_{1}\right)$ and $\operatorname{Ann}\left(\mathrm{R}_{2}\right)$, where $\operatorname{Ann}\left(\mathrm{R}_{1}\right):=\left\{\left(\mathrm{r}_{1}, \mathrm{r}_{2}\right) \in \mathrm{R}_{1} \times \mathrm{R}_{1} \mid \mathrm{r}_{1} \mathrm{r}_{2}=0\right\}$ and $\operatorname{Ann}\left(\mathrm{R}_{2}\right):=\left\{\left(\mathrm{s}_{1}, \mathrm{~s}_{2}\right) \in \mathrm{R}_{2} \times \mathrm{R}_{2} \mid \mathrm{s}_{1} \mathrm{~s}_{2}=0\right\}$, as follows:

$$
\begin{array}{r}
\text { Ann }=\left\{\left(\left(\mathrm{r}_{1}, \mathrm{~s}_{1}\right),\left(\mathrm{r}_{2}, \mathrm{~s}_{2}\right)\right) \in \mathrm{R} \times \mathrm{R} \mid\left(\mathrm{r}_{1} \mathrm{r}_{2}, \mathrm{~s}_{1} \mathrm{~s}_{2}\right)=(0,0)\right\}= \\
\left\{\left(\mathrm{r}_{1}, \mathrm{r}_{2}\right) \in \mathrm{R}_{1} \times \mathrm{R}_{1} \mid \mathrm{r}_{1} \mathrm{r}_{2}=0\right\} \times \\
\left\{\left(\mathrm{s}_{1}, \mathrm{~s}_{2}\right) \in \mathrm{R}_{2} \times \mathrm{R}_{2} \mid \mathrm{s}_{1} \mathrm{~s}_{2}=0\right\}=\operatorname{Ann}\left(\mathrm{R}_{1}\right) \times \operatorname{Ann}\left(\mathrm{R}_{2}\right) \\
\mathrm{P}(\mathrm{R})=\frac{|\operatorname{Ann}|}{|\mathrm{R} \times \mathrm{R}|}=\frac{\left|\operatorname{Ann}\left(\mathrm{R}_{1}\right) \| \operatorname{Ann}\left(\mathrm{R}_{2}\right)\right|}{\left|\mathrm{R}_{1} \times \mathrm{R}_{1} \| \mathrm{R}_{2} \times \mathrm{R}_{2}\right|}=\mathrm{P}\left(\mathrm{R}_{1}\right) \mathrm{P}\left(\mathrm{R}_{2}\right) .
\end{array}
$$

\section{The probability that two elements of $Z_{n}$ have product zero}

In this section $P\left(Z_{n}\right)$ will be found, where $Z_{n}$ is the ring of integers modulo $\mathrm{n}$. It is well known that if $\mathrm{n}=\mathrm{p}_{1}^{\mathrm{k}_{1}} \cdot \mathrm{p}_{2}^{\mathrm{k}_{2}} \cdots \mathrm{p}_{\mathrm{r}}^{\mathrm{k}_{\mathrm{r}}}$, then $\mathrm{Z}_{\mathrm{n}} \cong \mathrm{Z}_{\mathrm{p}_{1}} \times \mathrm{Z}_{\mathrm{p}_{2}} \times \cdots \times \mathrm{Z}_{\mathrm{p}_{\mathrm{r}}} \mathrm{k}_{\mathrm{r}}$. By Theorem 2.6, and by finding $\mathrm{P}\left(\mathrm{Z}_{\mathrm{p}^{\mathrm{k}}}\right)$, for some positive integer $\mathrm{k}$, the following holds. Theorem 3.1 $\mathrm{P}\left(\mathrm{Z}_{\mathrm{p}^{\mathrm{k}}}\right)=\frac{(\mathrm{k}+1) \mathrm{p}-\mathrm{k}}{\mathrm{p}^{\mathrm{k}+1}}$, where $\mathrm{p}$ is a prime and $\mathrm{k} \geq 1$

Proof. It is clear that the set of nonzero zero divisors of $Z_{p^{k}}$ is $\mathrm{S}:=\left\{\mathrm{p}, 2 \mathrm{p}, 3 \mathrm{p}, \cdots,\left(\mathrm{p}^{\mathrm{k}-1}-1\right) \mathrm{p}\right\}$ with size $\mathrm{p}^{\mathrm{k}-1}-1$. Rewrite the set $\mathrm{S}$ as the union of $\mathrm{k}-1$ disjoint sets $\mathrm{S}_{\mathrm{i}}$, $\mathrm{i}=1,2, \cdots, \mathrm{k}-1$, that is, $\mathrm{S}=\bigcup_{\mathrm{i}=1}^{\mathrm{k}-1} \mathrm{~S}_{\mathrm{i}}$, such that $\mathrm{S}_{\mathrm{i}}$ contains $m p^{i}, m \neq l p$, the multiple of $p$, and $m=1,2, \cdots, p^{k-i}-1$. Thus, the size of each $\mathrm{S}_{\mathrm{i}}$ is 
$\left(\mathrm{p}^{\mathrm{k}-\mathrm{i}}-1\right)-\left(\mathrm{p}^{\mathrm{k}-(\mathrm{i}+1)}-1\right)=\mathrm{p}^{\mathrm{k}-\mathrm{i}}-\mathrm{p}^{\mathrm{k}-(\mathrm{i}+1)}$. One can see that the product of any element of $S_{i}$ with every element of $\bigcup_{j=1}^{i} S_{k-j}$ is zero. So, the annihilator of each element of $S_{i}$ has size $p^{i}$. Hence $|\operatorname{Ann}|=|\operatorname{Ann}(0)|+\sum_{\mathrm{x} \in \mathrm{S}}|\operatorname{Ann}(\mathrm{x})|+\sum_{0 \neq \mathrm{x} \notin \mathrm{S}}|\operatorname{Ann}(\mathrm{x})|=$ $\mathrm{p}^{\mathrm{k}}+\sum_{\mathrm{i}=1}^{\mathrm{k}-1} \mathrm{p}^{\mathrm{i}}\left(\mathrm{p}^{\mathrm{k}-\mathrm{i}}-\mathrm{p}^{\mathrm{k}-(\mathrm{i}+1)}\right)+\left(\mathrm{p}^{\mathrm{k}}-1-\left(\mathrm{p}^{\mathrm{k}-1}-1\right)\right)=$ $\mathrm{p}^{\mathrm{k}}+\sum_{\mathrm{i}=1}^{\mathrm{k}-1}\left(\mathrm{p}^{\mathrm{k}}-\mathrm{p}^{\mathrm{k}-1}\right)+\left(\mathrm{p}^{\mathrm{k}}-\mathrm{p}^{\mathrm{k}-1}\right)=(\mathrm{k}+1) \mathrm{p}^{\mathrm{k}}-\mathrm{k} \mathrm{p}^{\mathrm{k}-1}$.

Therefore,

$P\left(Z_{p^{k}}\right)=\frac{|A n n|}{\left(p^{k}\right)^{2}}=\frac{p^{k-1}((k+1) p-k)}{p^{2 k}}=\frac{(k+1) p-k}{p^{k+1}}$.

Corollary 3.2 If $n=p_{1}^{k_{1}} \cdot p_{2}^{k_{2}} \cdots p_{r}^{k_{r}}$, then

$P\left(Z_{n}\right)=\prod_{i=1}^{r} \frac{\left(k_{i}+1\right) p_{i}-k_{i}}{p^{k_{i}+1}}$.

Proof. It is well known that if $n=p_{1}^{k_{1}} \cdot p_{2}^{k_{2}} \cdots p_{r}^{k_{r}}$, then $\mathrm{Z}_{\mathrm{n}} \cong \mathrm{Z}_{\mathrm{p}_{1}{ }_{1}} \times \mathrm{Z}_{\mathrm{p}_{2}} \times \cdots \times \mathrm{Z}_{\mathrm{p}_{\mathrm{r}}}{ }_{\mathrm{r}}$. By Theorem 2.6, $P\left(Z_{n}\right)=\prod_{i=1}^{r} P\left(Z_{p_{i}}\right)$. From Theorem 3.1, the result follows.

\section{CONCLUSION}

In this paper, the probability $\mathrm{P}(\mathrm{R})$ of two elements of a finite ring $\mathrm{R}$ have product zero has been introduced. The bounds of $\mathrm{P}(\mathrm{R})$ have been found. Also, the general formula of $\mathrm{P}(\mathrm{R})$ has been found in the case when $\mathrm{R}$ is the ring of integers modulo $\mathrm{n}$.

\section{ACKNOWLEDGEMENT}

The authors would like to thank the referee for his/her valuable comments.

\section{REFERENCES}

[1] Gustafson, W. H. 1973. What is the probability that two group elements commute? The American Mathematical Monthly. 80, 1031-1034.

[2] Rusin, D. 1979. What is the probability that two elements of a finite group commute? Pacific Journal of Mathematics. 82, 237-247.

[3] Lescot, P., de, D. 1988. Commutativité et structure d'un groupe fini (2). Rev. Math. Spéciales. 8, 276-279.

[4] Beck, I. 1988. Coloring of commutative rings. Journal of Algebra. 116(1), 208-226.

[5] Anderson, D. F., Livingston, P. S. 1999. The zero-divisor graph of a commutative ring. Lecture Notes in Pure and Appl. Math. 217(2), 434 447.

[6] Anderson, D. F., Levy, R. and Shapiro, J. 2003. Zero-divisor graphs, von Neumann regular rings, and Boolean algebras. Journal of Pure and Applied Algebra. 180(3), 221-241.

[7] Livingston, P. S. 1997. Structure in zero-divisor graphs of commutative rings. Master's Thesis, University of Tennessee.

[8] Esmkhani, M. A., Jafarian Amiri, S. M. 2018. The probability that the multiplication of two ring elements is zero. Journal of Algebra and Its Applications. 17(3), 1850054(9 pages). 